American Journal of Biochemistry and Biotechnology 3 (4): 180-186, 2007

ISSN 1553-3468

(C) 2007 Science Publications

\title{
Pharmacophore Pattern Identification of Tachykinin Receptor Selective Peptide Agonists: Implications in Receptor Selectivity
}

\author{
${ }^{1}$ Anjali Dike, ${ }^{2}$ Indu R. Chandrashekaran, ${ }^{3}$ Anil K. Mantha, ${ }^{1}$ Najma Z. Baquer, and ${ }^{4}$ Sudha M. Cowsik \\ ${ }^{1}$ School of Life Sciences, Jawaharlal Nehru University, New Delhi-110067, INDIA \\ ${ }^{2}$ Structural Biology Division, The Walter and Eliza Hall Institute of Medical Research, Parkville, Victoria, Australia \\ ${ }^{3}$ BMB, University of Texas Medical Branch Galveston, Texas, USA \\ ${ }^{4}$ Department of Biochemistry and Molecular Biophysics, Washington University School of Medicine, St. Louis, MO
}

\begin{abstract}
The mammalian tachykinin (TK) peptides and their three Neurokinin (NK1, NK2 and NK3) receptors represent an effector system with wide-ranging actions on neuronal, airway smooth muscle, mucosal, endothelial, immune, inflammatory and remodeling cell function. Recent clinical and preclinical data suggests the pathophysiological role of TKs in various diseases including asthma, emesis and depression. The TK-NK receptor interactions and overlapping functions mediated by each NK receptor indicate added therapeutic benefit of using multiple NK receptor blockade. In the absence of structural data on neurokinin receptors, the membrane-induced structure of tachykinins play an important role as a first step towards understanding structure-activity relationship. A comparison of the conformational features of different NK1, NK2 and NK3 receptor agonists highlights several features which might be responsible for determining selectivity for the particular receptor subtype. An attempt has been made to correlate the observed conformational differences to the binding ability and biological activity of various NK1, NK2 and NK3 receptor agonists. The membrane bound conformations of tachykinins have been used as a starting point, leading to useful pharmacophore patterns that can be used for identifying lead structures with novel scaffolds.
\end{abstract}

Key words: $\quad$ Tachykinin, Neuropeptide, Neurokinin receptor, Pharmacophore pattern, Solution conformation

\section{INTRODUCTION}

Tachykinins constitute the largest neuropeptide family with multifunction in central and peripheral tissues. Tachykinins have been found in many different species across Bilateria, from invertebrates to mammals [1], suggesting that tachykinin motif has been widely exploited throughout evolution ${ }^{[3,4]}$. This family is characterized by a common C-terminal sequence, Phe$\mathrm{X}$-Gly-Leu-Met-NH2, where $\mathrm{X}$ represents either an aromatic (Phe, Tyr) or a branched aliphatic (Val, Ile) amino acid. The C-terminal region or the message domain is believed to be responsible for activating the receptor whereas the divergent $\mathrm{N}$-terminal region or the address domain varies in amino acid sequence and length and is postulated to play a role in determining the receptor subtype specificity ${ }^{[2]}$. The best known members are mammalian tachykinins Substance P (SP), Neurokinin A (NKA) and Neurokinin B (NKB) followed by tachykinins from non-mammalian sources Physalaemin, Eledoisin and others (Table 1).
Table 1: Members of tachykinin neuropeptide family

\begin{tabular}{|c|c|c|c|}
\hline Source & Tachykinin & Sequence & Receptor \\
\hline \multirow[t]{5}{*}{ Mammal } & $\begin{array}{l}\text { Substance P } \\
\text { (SP) }\end{array}$ & $\begin{array}{l}\text { R-P-K-P-Q-Q-F-F-G-L- } \\
\text { M- NH2 }\end{array}$ & NK1 \\
\hline & $\begin{array}{l}\text { Neurokinin A } \\
\text { (NKA) }\end{array}$ & $\begin{array}{l}\text { H-K-T-D-S-F-V-G-L- } \\
\text { M-NH2 }\end{array}$ & NK2 \\
\hline & $\begin{array}{l}\text { Neurokinin B } \\
\text { (NKB) }\end{array}$ & $\begin{array}{l}\text { D-M-H-D-F-F-V-G-L- } \\
\text { M-NH2 }\end{array}$ & NK3 \\
\hline & Neuropeptide K & $\begin{array}{l}\text { D-A-D-S-S-I-E-A-Q-V- } \\
\text { A-L-L-K-A-L-Y-G-H- } \\
\text { G-Q-I-S-H-K-R-H-K-T- }\end{array}$ & $\begin{array}{c}\mathrm{NK} 1 / \mathrm{NK} \\
2\end{array}$ \\
\hline & Neuropeptide & $\begin{array}{l}\text { D-S-F-V-G-L-M-NH2 } \\
\text { D-A-G-H-G-Q-I-S-H- } \\
\text { K-R-H-K-T-D-S-F-V- } \\
\text { G-L-M-NH2 }\end{array}$ & NK2 \\
\hline \multirow[t]{3}{*}{$\begin{array}{l}\text { Amphibi } \\
\text { an }\end{array}$} & $\begin{array}{l}\text { Phyllomedusin } \\
\text { Physalaemin }\end{array}$ & $\begin{array}{l}\text { B-P-N-P-N-R-F-I-G-L- } \\
\text { M-NH2 }\end{array}$ & NK1 \\
\hline & Uperolein & $\begin{array}{l}\text { B-A-D-P-N-K-F-Y-G- } \\
\text { L-M-NH2 }\end{array}$ & NK1 \\
\hline & & $\begin{array}{l}\text { B-P-D-P-N-A-F-Y-L- } \\
\text { M-NH2 }\end{array}$ & NK1 \\
\hline Dogfish & $\begin{array}{l}\text { Scyliorhinin I } \\
\text { Scyiorhinin II }\end{array}$ & $\begin{array}{l}\text { A-K-F-D-K-F-Y-G-L- } \\
\text { M-NH2 } \\
\text { S-P-S-N-S-K-C-P-D-G- } \\
\text { P-D-C-F-V-G-L-M- } \\
\text { NH2 }\end{array}$ & $\begin{array}{c}\mathrm{NK} 1 / \mathrm{NK} \\
2 \\
\mathrm{NK} 3\end{array}$ \\
\hline Octopod & Eledoisin & $\begin{array}{l}\text { B-P-S-K-D-A-F-I-G-L- } \\
\text { M-NH2 }\end{array}$ & $\begin{array}{c}\text { NK2/NK } \\
3\end{array}$ \\
\hline
\end{tabular}

Corresponding Author: $\quad$ Prof. Sudha M Cowsik, School of Life Sciences, Jawaharlal Nehru University, New delhi-110067. INDIA 
The tachykinins have been shown to elicit wide array of activities such as powerful vasodilatation, hypertensive action and stimulation of extra vascular smooth muscle and are known to be involved in variety of clinical conditions including chronic pain, Parkinson's disease, Alzheimer's disease, depression, rheumatoid arthritis, irritable bowel syndrome and asthma ${ }^{[4]}$. The broad spectrum of action of tachykinins is attributed to the lack of selectivity of tachykinins for their receptors. The three distinct G-protein coupled receptor subtypes (designated as NK1, NK2 and NK3) have been cloned and characterized for tachykinins $[5,6,7]$. While SP has highest affinity for the NK1 type, NKA and NKB are the endogenous ligands that exhibit the highest affinity for the Neurokinin 2 (NK2) and Neurokinin 3 (NK3) binding sites respectively. The conformational features of tachykinins, which control receptor binding and influence their biological activity, are of significant interest, particularly as the selectivity of these peptides for different receptor sites is not fully understood. ${ }^{[8,9]}$. Identification of structural features of the agonists important for receptor binding and biological activity is of great significance in unraveling the molecular mechanisms involved in tachykinin receptor activation and also in rational design of novel therapeutic agents.

Binding of tachykinin peptide to its receptor occurs in the membrane environment. Membrane is proposed to induce a specific conformation on the peptide before interacting with its receptor and this conformational alteration may be an essential step for the recognition by the receptor ${ }^{[10,11]}$. Bioactive conformation of tachykinin neuropeptides has been extensively investigated using high-resolution nuclear magnetic resonance (NMR), circular dichroism (CD) and Infrared (IR) spectroscopy. Solution structure for SP, NKA, NKB, Physalaemin, Eledoisin and various naturally derived or synthetic analogues has been reported in various membrane mimetic solvents ${ }^{[12-25]}$.

We present here a brief summary of threedimensional structure of tachykinin neuropeptides (NK1, NK2 and NK3 receptor agonists) bound to dodecylphosphocholine (DPC) micelles, one of the well-characterized model membrane systems, using two-dimensional NMR spectroscopy. A comparison of conformational features of different NK1, NK2 and NK3 receptor agonists highlights several features which may be responsible for determining selectivity for the particular receptor subtype. An attempt has been made to correlate the observed conformational differences to the binding ability and biological activity of various NK1, NK2 and NK3 receptor agonists. The membrane bound conformations for tachykinins have been used as a starting point, leading to useful pharmacophore patterns that can be used for identifying lead structures with novel scaffolds.

NK1 receptor selective peptide Agonist: The solution conformation of NK1 agonists, SP, Uperolein, Phyllomedusin, Physalaemin and Eledoisin bound to DPC micelles have been determined using two dimensional NMR spectroscopy $[17,20,26,27]$. The conformation of these NK1 agonists supports the available structure-activity and receptor-ligand interaction data. A common structural scaffold has been identified on comparing the solution conformation of Uperolein and Phyllomedusin with the conformation of the potent NK1 agonist, SP ${ }^{[17]}$, Physalaemin ${ }^{[27]}$ and Eledoisin ${ }^{[20]}$ in the membrane environment. The structure adopted by SP and Physalaemin bound to DPC micelles is comprised of a helical mid-region with an extended C-terminus. Seelig and co-workers $[28,29]$ have suggested that the hydrophobic (Phe7, Phe8, Leu10) and a hydrophilic (Gln6, Gly9) side chains in the C-terminus position SP in the receptor-binding site in such a fashion as to lead to optimal binding. A similar amphipathic helix towards middle region is observed in Uperolein with hydrophobic residues (Phe7, Tyr8, Leu10) on one side and the hydrophilic residues (Asn5, Ala6) on the other side, which probably makes it selective for NK1 receptor (Figure 1.1). Phyllomedusin lacks the Phe 8 residue of SP and instead has an Ile residue, which extends the helix length to include Gly 8, Leu 9 and Met 10. A similar increase in helix length is observed in other NK1 agonists like Uperolein, Physalaemin and Eledoisin ${ }^{[20,}$ ${ }^{30]}$. Such a change in the helix length alters the positions of the hydrophobic and hydrophilic side chains in the C-terminus, decreasing the ability of Physalaemin, Uperolein and Eledoisin to bind effectively to the NK1 receptor (Figure 1). Furthermore, stabilization of helix through an increase in helix length results in a reduction of flexibility of message domain, a situation determined to be unfavorable for NK1 receptor binding ${ }^{[29]}$. Conventional binding assays have shown that SP is the preferred ligand for NK1 receptor and Phyllomedusin, Eledoisin, Physalaemin and Uperolein bind with orders of magnitude much weaker than SP. The reduced binding efficiency of these NK1 agonists at NK1 receptor can be attributed to the increase in helix length in these peptides. It is interesting to note that even a small change (for instance, from Phe8 in SP to Tyr8 in Uperolein in the C-terminus) has substantial influence on the conformation of peptide chain making a peptide less potent agonist for NK1 receptor. 


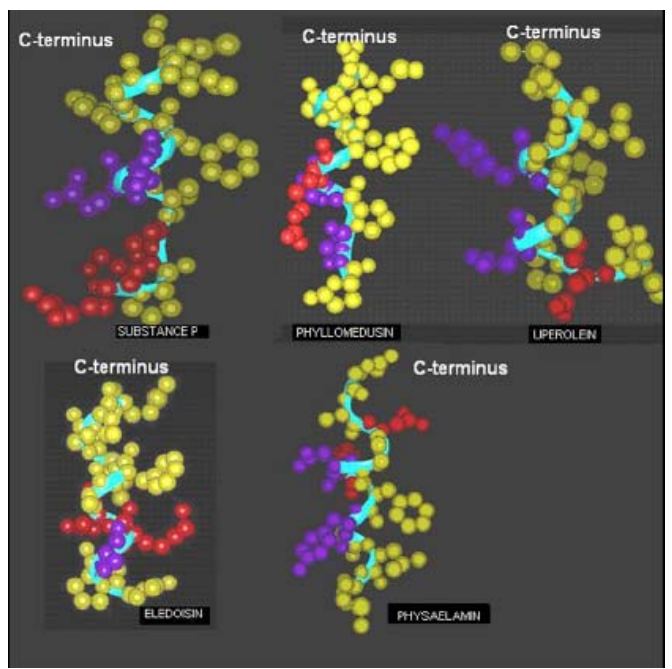

Fig. 1: A graphic representation of the lipid bound conformation of different NK1 agonists Phyllomedusin, SP, Eledoisin, Uperolein and Physaelamin. The peptide backbone is shown as a ribbon tube (blue). Ionic residues are colored red, polar residues are colored purple and the hydrophobic residues are colored yellow. The helical segment is clearly visible.

On the basis of the available structure-activity studies and the observed conformational features a pharmacophore hypothesis for the NK1 selective peptide agonists has been proposed. The fundamental principle underlying a pharmacophore hypothesis is that the ligands acting at the same receptor site show similar chemical functionality in an analogous position in space [31]. A three point pharmacophore pattern has been generated using Substance P, Physaelamin, Phyllomedusin and Uperolein as the template. A hydrophobic aromatic feature has been positioned on to the ring of Phe and a hydrophobic feature has been placed on the side chain of Asn and on the ring of Pro. Notably these residues have been shown to be important for NK1 selectivity ${ }^{[3]}$. The distance between the pharmacophore points in all the four NK1 selective agonists were compared and the values are reported in Table 2 Eledoisin does not have a conserved Proline residue, however it has a similar spatial relationship between Phe and Asp residue. It was observed that a similar spatial relationship between these pharamacophore points exists in NK1 selective peptides with a distance tolerance of \pm 1.5 to $\pm 0.5 \AA$. It has been inferred that NK1 selective agonists share a common pharmacophore pattern defined by the helical mid region Pro, Asn and Phe residues (Fig. 2). The amino acid side chain of these residues represents key chemical features, which in the correct spatial arrangement may be the prerequisite for binding and activation of NK1 receptor.

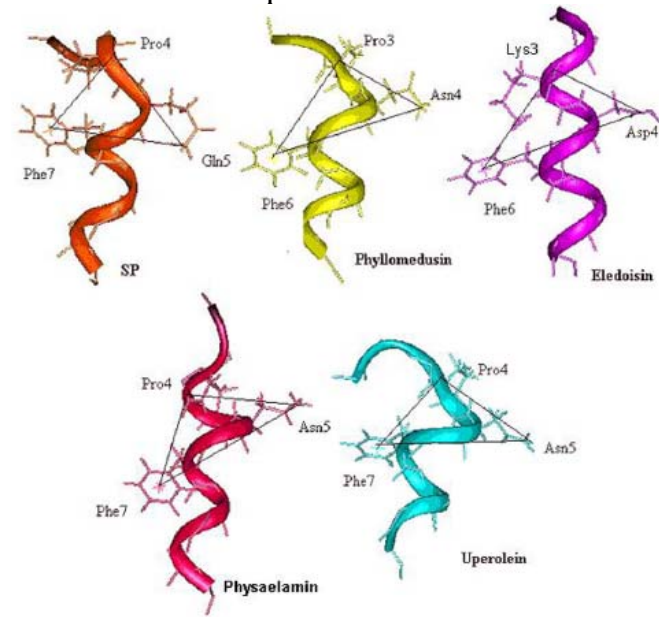

Fig. 2: Pharmacophore pattern in NK1 agonists: Substance P (SP), Physaelamin, Phyllomedusin, Eledoisin, Uperolein. The common scaffold exists towards the central region of the peptides.

Table 2: Distances between the proposed pharmacophore points in NK1 peptide agonists

\begin{tabular}{|c|c|c|c|}
\hline $\begin{array}{c}\text { Pharmacophore } \\
\text { Points }\end{array}$ & $\begin{array}{c}\text { Pro:N/F:QR } \\
(\AA)\end{array}$ & $\begin{array}{c}\text { Asn/Gln:N } \delta 2 \\
/ \mathrm{F}: \mathrm{QR}(\AA)\end{array}$ & $\begin{array}{c}\text { Asn/Gln:N } \delta 2 / \\
\text { Pro:N }(\AA)\end{array}$ \\
\hline Substance P & 6.93 & 12.15 & 7.72 \\
\hline Physaelamin & 6.49 & 11.10 & 6.60 \\
\hline Phyllomedusin & 7.76 & 11.00 & 6.32 \\
\hline Uperolein & 6.48 & 10.87 & 7.07 \\
\hline
\end{tabular}

NK2 receptor selective peptide agonists: The solution conformation of NK2 agonists, NKA, NP $\gamma$ and NPK bound to DPC micelles have been determined by two dimensional NMR spectroscopy ${ }^{[21,23,25]}$. On comparing the DPC bound conformations of potent NK2 agonist NPK with that of NKA and NP $\gamma$, it is observed that a similar $\beta$ turn preceding the helical core in the $\mathrm{C}$ terminus is present in all the NK2 agonists ${ }^{[21,23]}$. The presence of an $\alpha$-helix in the $\mathrm{C}$ terminal region and turn like structures in $\mathrm{N}$ terminal region present the consensus structural feature of NK2 selective agonists and may be of significance in attributing NK2 receptor selectivity (Fig. 3). In contrast to NK1 agonists, it is interesting to note that the helix length for $\mathrm{C}$ terminus is increased in all the NK2 selective agonists, thus probably reducing the selectivity for NK1 receptor. The presence of an aliphatic amino acid in the NK2 agonists instead of an aromatic residue in the position analogous to Phe 8 residue of SP, may also contribute to the reduced selectivity for NK1 receptor. 
On the basis of the available structure-activity studies and the observed conformational features a pharmacophore hypothesis for the NK2 selective peptide agonists has been proposed. Similar to NK1 selective agonists a three point pharmacophore pattern has been generated using NPK, NP $\gamma$ and NKA as the template. A hydrophobic aromatic feature has been positioned on to the ring of phenylalanine and a hydrophobic feature has been placed on the side chains of Met and Leu. Table 3 shows that a similar spatial relationship between these pharamacophore points exists in NK2 selective peptides with distance tolerance of \pm 1.5 to $\pm 0.5 \AA$. It is inferred that NK2 selective agonists share a common pharmacophore pattern defined by Phe, leu and Met residues in the conserved C-terminal message domain (Fig. 4).

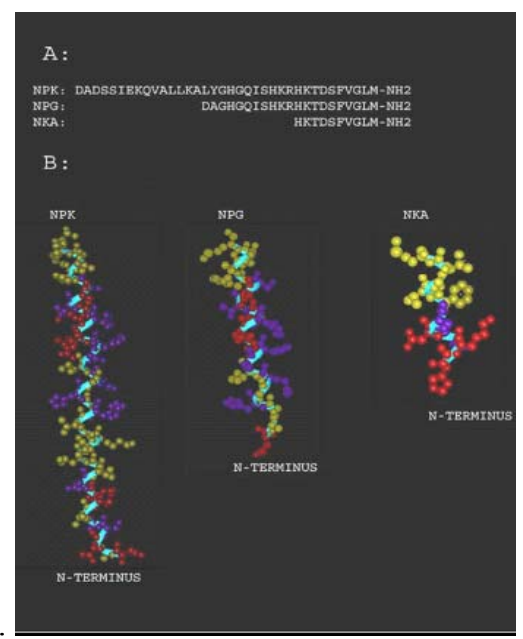

Fig. 3: Sequence alignment and a graphic representation of lipid bound conformation of NPK compared with NP $\gamma$ and NKA (NK2 agonists). The peptide backbone is shown as a ribbon tube (blue). Ionic residues are coloured red, polar residues are coloured purple and the hydrophobic residues are coloured yellow. The helical segment is clearly visible.

\subsection{NK3 receptor selective peptide agonists}

Structure-activity studies on NK3 selective agonists have not been reported as extensively as for NK1 and NK2 receptor agonists. Solution conformation of potent $\mathrm{NK} 3$ agonist, $\mathrm{NKB}^{[22]}$ and Scyliorhinin II (unpublished data from our group) has been obtained. Membrane bound conformation of NKB shows that the complete $\mathrm{C}$ as well as N-terminal adopts helical conformation. The structure of Scy II bound to DPC micelles indicates a helical conformation in the C-terminus stabilized by the disulfide bond (Fig. 5).

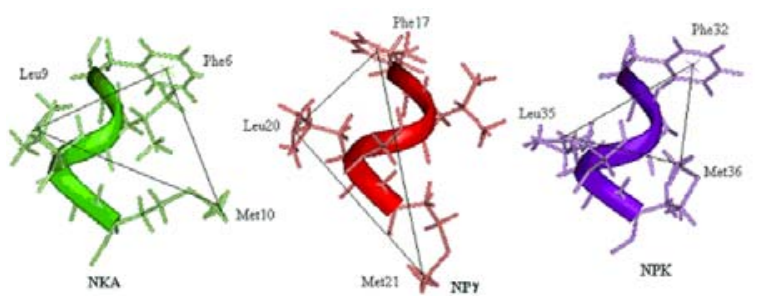

Fig. 4: Pharmacophore pattern in NK2 agonists: NKA, NP $\gamma$, NPK. The common scaffold exists towards the C-terminal message domain of the peptides.

Table 3: Distances between the proposed pharmacophore points in NK2 peptide agonists

\begin{tabular}{cccc}
\hline $\begin{array}{c}\text { Pharmacophore } \\
\text { points }\end{array}$ & $\begin{array}{c}\text { Phe:QR/Leu } \\
(\AA)\end{array}$ & $\begin{array}{c}\text { Met/Leu } \\
(\AA)\end{array}$ & $\begin{array}{c}\text { Phe:QR/Met } \\
(\AA)\end{array}$ \\
\hline NKA & 6.39 & 10.23 & 9.96 \\
NP $\gamma$ & 6.86 & 9.97 & 11.81 \\
NPK & 7.87 & 9.66 & 9.17 \\
\hline
\end{tabular}

Ionic interactions are proposed to play an important role in NK3 receptor selectivity ${ }^{[32]}$ and the presence of overall negative charge on Scy II and NKB in contrast to other tachykinins probably makes them more selective for NK3 receptor. A three point pharmacophore pattern has been generated using NKB and Scy II as the template.

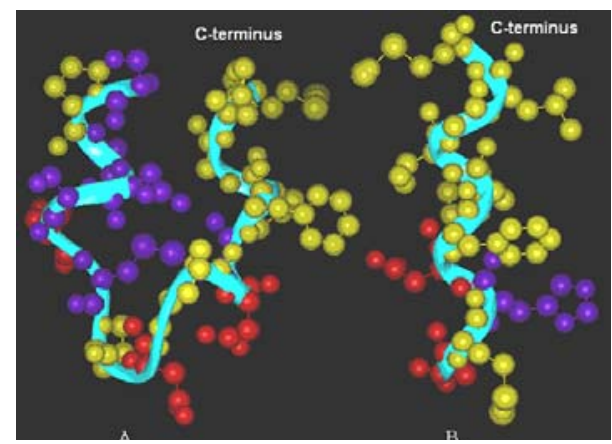

Fig. 5: Graphic representation of lipid bound conformation of (A) Scy II compared with (B) NKB (NK3 agonists). The peptide backbone is shown as a ribbon tube (blue). Ionic residues are coloured red, polar residues are coloured purple and the hydrophobic residues are coloured yellow. The helical segment is clearly visible.

A hydrophobic aromatic feature has been positioned on to the ring of phenylalanine and a hydrophobic feature has been placed on the side chains of Met and Leu. Table 4 shows that a similar spatial relationship exists between these pharamacophore points in NK3 selective peptides with distance tolerance 
of \pm 1.5 to $\pm 0.5 \AA$. It is inferred that NK3 selective agonists share a common pharmacophore pattern defined by Phe, Leu and Met residues in the conserved C-terminal message domain (Fig. 6).

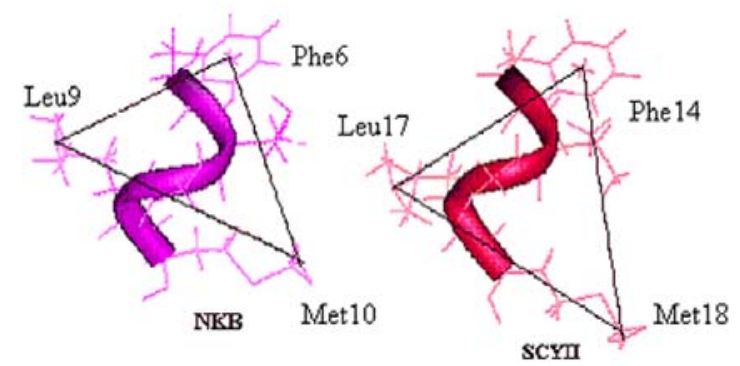

Fig. 6: Pharmacophore pattern in NK3 agonists: Neurokinin B (NKB), Scyliorhinin II (Scy II). The common scaffold exists towards the C-terminal message domain of the peptides.

Table 4: Distances between the proposed pharmacophore points in NK3 peptide agonists.

\begin{tabular}{lccc}
\hline $\begin{array}{l}\text { Pharmacophore } \\
\text { points }\end{array}$ & $\begin{array}{c}\text { Phe:QR/Leu } \\
(\AA)\end{array}$ & $\begin{array}{c}\text { Met/Leu } \\
(\AA)\end{array}$ & $\begin{array}{c}\text { Phe:QR/Met } \\
(\AA)\end{array}$ \\
\hline Scy II & 9.01 & 11.26 & 11.26 \\
NKB & 8.06 & 11.15 & 10.96 \\
\hline
\end{tabular}

Dual NK1/NK2 selective agonist : Scyliorhinin I, a dual NK1/NK2 selective agonist can be considered as one of the important tools in tachykinin study. Scy I contain two Lys residues that would result in a more favorable interaction with the anionic fixed-charge compartment of the plasma membrane and greater access to NK1 and NK2 receptors ${ }^{[2] .}$

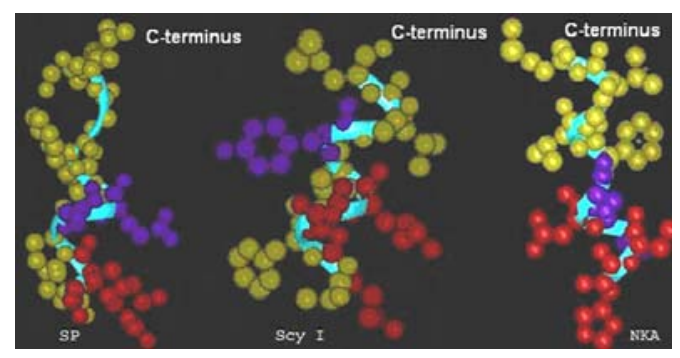

Fig 7: A graphic representation of the lipid bound conformation of Scy I compared with SP (potent NK1 agonist) and NKA (potent NK2 agonist). The peptide backbone is shown as a ribbon tube (blue). Ionic residues are coloured red, polar residues are coloured purple and the hydrophobic residues are coloured yellow. The helical segment is clearly visible.
It is proposed that the "non polar" nature of Tyr side chain at Position 7 of Scy I confers selectivity for NK2 receptor binding where as the aromatic ring of Tyr is important for NK1 binding. Absence of Pro residue at position 4 from the $\mathrm{N}$-terminus (as is present in majority of NK1 receptor agonists: SP, Physaelamin, Uperolein), adjacent to the crucial neutral or basic residue occupying position 3 ("Lys" in SP, NKA and Scy I) can be considered favorable for binding to NK2 receptors. Aspartate residue in Scy I analogous to residue 5 in SP and residue 4 in NKA may be involved in ionic interaction thus contributing to the binding energy for NK2 agonists [32,33]. The overall comparison and correlation with NK1 and NK2 agonist (SP and NKA respectively) indicates that the conformation adopted by Scy I in presence of DPC micelles presents the structural motif typical of NK1/NK2 dual selective agonists (Fig. 7).

\section{CONCLUSION}

The structural studies on neurokinin selective peptide agonists are well in accordance with the membrane compartment theory proposed by Schwyzer ${ }^{[34]}$ and suggest that the target cell membrane indeed induces preferred conformations and orientations of peptides by preferential interaction with the different membrane compartments. The results correlate well with the membrane mediated selectivity predicted by Schwyzer ${ }^{[2]}$ for NK1, NK2 and NK3 receptor selectivity. According to Schwyzer's hypothesis for neurokinin receptors, NK1 sites require hydrophobic membrane association of the peptide message segments as perpendicularly oriented $\alpha$-helical domains, whereas the hydrophilic address segments remain in contact with the aqueous phase. Electrostatic accumulation of the peptide message segment in the anionic fixed charge layer of the membrane, which is located between the bulk aqueous phase and the hydrophobic compartment, facilitates interaction with NK2 sites. It attenuates the interaction with NK3 sites, which require peptides with zero or negative charges. Therefore it can be suggested that the membrane structure of a peptide agonist (its accumulation, conformation and orientation on an aqueous-hydrophobic interface or membrane surface) is important for the study of structureconformation-activity relationships.

The biological relevance of membrane-induced structure of peptide hormones has been widely debated and several questions have been raised as to whether the structure of these peptides in presence of lipid is similar to the structure of these peptides at the receptor ${ }^{[35]}$. However, this can be answered conclusively only 
after a direct investigation of the structure of the peptide-receptor complex is undertaken. Recently a comparison of the receptor-bound and micelle-bound states of a peptide hormone indicated only small differences in the conformation ${ }^{[1]}$. This investigation clearly indicated membrane association as the initial step in ligand receptor interaction and membrane induced prefolding of the ligand into a bioactive conformation, thereby offering a very strong support for our investigation. Nevertheless, we would like to stress that since the structural features of the peptide ligand have been determined in isolation, there could be conformational changes to the structure upon interaction with the receptor. However these structural features which seem to be essential for the biological activity, will probably be maintained until peptide agonist approaches its receptor.

Structural data from this study gives a basis to design the strategy to further investigate specific interactions between tachykinin ligand and receptor through transferred NOE NMR experiments and other advanced NMR techniques. The results presented here can also be used as an initial starting point for structure based drug design for tachykinin receptors. Apart from the starting point for structure-activity relationship studies, the high structural similarity observed in tachykinin peptides isolated from mammals to amphibians indicates the structural conservation during evolution. This suggests a strong selective pressure. This study can therefore also be used to establish the phyllogenetic relationships of different tachykinin peptides.

\section{ACKNOWLEDGMENT}

Anjali Dike acknowledges the financial support in the form of Senior Research Fellowship from the Council of Scientific and Industrial Research, India. This work is supported through a grant from the Department of Science and Technology, Government of India.

\section{REFERENCES}

1. Pennefather J. N, Lecci A., Candenas M. L., Patak E., Pinto F. M. and Maggi C. A. 2004. Tachykinins and tachykinin receptors: a growing family. Life Sc. 74:1445-1463.

2. Schwyzer, R. 1987. Membrane-assisted molecular mechanism of neurokinin receptor subtype selection. EMBO J. 6: 2255-2259

3. Severini, C., Improta, G., Falconieri-Erspamer, G., Salvadori, S. and Erspamer, V. 2002. The tachykinin peptide family. Pharmacol. Rev. 54 (2): 285-322
4. Satake, H and Kawada, T. 2006. Overview of the primary structure, tissue-distribution, and functions of Tachykinins and their receptors. Current Drug Targets, 7, 963-974.

5. Nakanishi, S. 1991. Mammalian tachykinin receptors. Annu Rev Neurosci. 14:123-136

6. Masu, Y., Nakayama, K., Tamaki, H., Harada, M., uno, Y. and Nakanishi, S. 1987. cDNA cloning of bovine substance-K receptor through oocyte expression system Nature. 329: 836-838.

7. Hanley, M.R., and Jackson, T. 1987. Substance K receptor: return of the magnificent seven. Nature. 329: 766-767.

8. Maggi, C.A., Patacchini, R., Rovero, $\mathrm{P}$ and Giachetti, A. 1993. Tachykinin receptors and Tachykinin receptor antagonists. J. Auton. Pharmacol. 13, 23.

9. Watson, S.P. and Guard, S., 1991. Tachykinin receptor types: classification and membrane signaling mechanisms. Neurochem. 18, 149.

10. Maurer, T., and Rüterjans, H. 1994. Solution structure of seminal plasmin in the presence of micelles. Eur. J. Biochem. 220: 111-116.

11. Inooka, H., Ohtaki, T., Kitahara, O., Ikegami, T., Endo, S., Chieko, K., Ogi, K., Onda, H., Fujino, M. and Shirakawa, M. 2001. Conformation of a peptide ligand bound to its G-protein coupled receptor. Nature structural Biology. 8(2): 161-165

12. Convert, O., Ploux, O., Lavielle, S., Cotrait, M. and Chassaing, G. 1988. Analysis of tachykininbinding site interactions using NMR and energy calculation data of potent cyclic analogues of substanceP. Biochim. Biophys. Acta. 954: 287302

13. Convert, O., Duplaa, H., Levielle, S. and Chassaing, G. 1991. Influence of the replacement of amino acid by its D-enantiomer in the sequence of substance P:Conformational analysis by NMR and energy calculations. Neuropeptides.19: 259270

14. Seelig, A. 1992. Interaction of a substance $P$ agonist and of substance $\mathrm{P}$ antagonists with lipid membranes: A thermodynamic analysis. Biochemistry. 31: 2897-2904

15. Ananthanarayanan, V. S., and Orlicky S. 1992. Interaction of substance $\mathrm{P}$ and its $\mathrm{N}$ - and $\mathrm{C}$ terminal fragments with $\mathrm{Ca}^{2+}$ : implications for hormone Biopolymers. 32: 1765-1773

16. Horne, J., Sadek, M. and Craik, D. J. 1993. Determination of the solution structure of neuropeptideK by high-resolution nuclear magnetic resonance spectroscopy. Biochemistry. 32: 74067412 . 
17. Cowsik, S. M., Lucke, C. and Ruterjans, H. 1997. Lipid-induced conformation of substance P. J. Biomol. Struct. Dyn. 15: 27-36

18. Whitehead, T. L., McNair, S. D., Hadden, C. E., Young, J. K and Hicks, R. P. 1998. Membraneinduced secondary structures of neuropeptides: a comparison of the solution conformations adopted by agonists and antagonists of the mammalian tachykinin NK-1 receptor. J. Med. Chem. 41: 1497-1506

19. Grace, C. R., Lynn, A. M. and Cowsik, S. M. 2001. Lipid induced conformation of tachykinin peptide kassinin. J. Biomolecular Str. And Stereodynamics. 18(4): 611-625

20. Grace, C. R., Chandrashekar, I. R. and Cowsik, S. M. 2003. Solution structure of the tachykinin peptide eledoisin. Biophysical . J. 84(1): 655-664

21. Chandrashekar, I. R. and Cowsik, S. M. 2003. Three dimensional structure of the mammalian tachykinin peptide Neurokinin A bound to lipid micelles. Biophys. J. 85(6): 4002-4011

22. Mantha, A. K., Chandrashekar, I. R., Baquer, N. Z. and Cowsik, S. M. 2004. Three Dimensional Structure of the Mammalian Tachykinin Peptide Neurokinin B Bound to Lipid Micelles. J. Biol. Str. Dyn .22(2): 137-147.

23. Chandrashekar, I.R., Dike, A and Cowsik, S.M. 2004. Membrane induced structure of the mammalian Tachykinin neuropeptide gamma. J. Structural Biology. 148: 315-325.

24. Dike, A and Cowsik, S.M. 2005. MembraneInduced structure of Scyliorhinin I: A dual NK1/NK2 agonist. Biophysical Journal. 88:35923600 .

25. Dike, A and Cowsik, S.M. 2006(a). ThreeDimensional structure of Neuropeptide K bound to dodecyl phosphocholine micelles. Biochemistry. 45(9): 2994-3004.

26. Dike, A and Cowsik, S.M. 2006(b).Solution structure of Amphibian tachykinin Uperolein bound to DPC micelles. J Structural Biology. 156(3): 442-452.
27. Mahajan, S., Lucke, C and Ruterjans, H.1993. Lipid induced conformation of physaelamin, J. Biomolecular Str. and Stereodynamics, 113.

28. Seelig, A., and Macdonald, P. M. 1989. Binding of a neuropeptide, substance $P$, to neutral and negatively charged lipids. Biochemistry. 28: 24902496.

29. Seelig, A., Alt, T., Lotz, S. and Holzemann, G. 1996. Binding of substance $P$ agonists to lipid membranes and to the neurokinin-1 receptor. Biochemistry. 35: 4365-4374.

30. Wilson J.C, Nielsen K.J, McLeish M.J, Craik D.J. 1994. A determination of the solution conformation of the nonmammalian tachykinin eledoisin by NMR and CD spectroscopy.Biochemistry. 33(22):6802-11.

31. Beusen, D.D. and Marshall, G.R. 2000. In Pharmacophore perception, development, and use in drug design; Guner, O.F., Ed; International University Line; La Jolla, CA. 21-45.

32. Cascieri, M.A., Huang, R.R., Fong, T.M., Cheung, A.H., Sadowski, S., Ber, E and Strader, C.D. 1992. Determination of the amino acid residues in substance $\mathrm{P}$ conferring selectivity and specificity for the rat neurokinin receptors. Mol Pharmacol. 41(6): 1096-1099.

33. Buck, S.H and Shatzer, S.A. 1988. Agonist and antagonist binding to tachykinin peptide NK2 receptors. Life Sci. 42(26):2701-2708.

34. Schwyzer, R., Erne, D. and Rolka, K. 1986. Prediction of preffered conformation, orientation and accumulation of Substance $\mathrm{P}$ on lipid membranes. Helv. Chim. Acta. 69: 1789-1797.

35. Marshall, R.G. 2001. Peptide interactions with Gprotein coupled receptors. Biopolymers. 60:246277. 